\title{
PAPEL DA ESCOLA PÚBLICA E DOS PROFESSORES: UMA ANÁLISE A PARTIR DA VOZ DOS PROFISSIONAIS DA EDUCAÇÃO
}

\author{
Larissa Teixeira, Vanda Moreira Machado Lima
}

Universidade Estadual Paulista - UNESP, Departamento de Educação, Curso de Pedagogia, Presidente Prudente, SP. Agência de fomento: FAPESP. E-mail: larissa.640@hotmail.com

\section{RESUMO}

O texto visa apresentar a opinião de um grupo de profissionais da educação, de uma escola pública municipal, a respeito do papel da escola pública municipal e dos professores dos anos iniciais do ensino fundamental. Esse trabalho resultou de uma pesquisa desenvolvida no ano de 2014 que buscou identificar as necessidades formativas dos profissionais da educação que subsidiou uma ação de formação continuada envolvendo: equipe gestora, professores e funcionários. A pesquisa se insere na abordagem qualitativa, e utilizou como instrumentos na coleta de dados a pesquisa bibliográfica e o questionário. Para categorização e análise das questões abertas recorremos à técnica de análise de conteúdo (FRANCO, 2008), na qual elaboram-se as categorias a partir da análise da resposta escrita dos sujeitos. Constatamos a partir da voz desses profissionais que sua compreensão do papel da escola foca-se como transmissão de conhecimentos, faz-se necessário refletir e discutir junto a esses profissionais que a escola deve articular a aquisição de conhecimentos e a formação do cidadão na dimensão individual e social. Verificamos que a parceria entre a escola pública e a universidade nesta pesquisa propiciou o desenvolvimento profissional de todos, os sujeitos da escola (professores, equipe gestora) e da universidade (pesquisador e bolsistas).

Palavras- chave: Escola pública municipal. Professores dos anos iniciais. Equipe gestora.

\section{THE ROLE OF PUBLIC SCHOOL AND TEACHERS: AN ANALYSIS FROM THE VOICE OF EDUCATION PROFESSIONALS}

\begin{abstract}
The text aims to present the opinion of a group of education professionals in a public school, about the role of public school and teachers in the early years of elementary school. This work resulted from a survey conducted in 2014 aimed at identifying the training needs of education professionals that supported an action involving continuing education: managing staff, faculty and staff. The survey is included in the qualitative approach, and used as instruments to collect data to literature and the questionnaire. For categorization and analysis of the open questions we used the content analysis technique (FRANCO, 2008), in which elaborate the categories by analyzing the written response of the subjects. We note from the voice of these professionals their understanding of the school's role focuses as transmission of knowledge, it is necessary to reflect and discuss with these professionals that the school should involve the acquisition of knowledge and the training of citizens in the individual and social. We note that the partnership between the public school and the university in this research led to the professional development of all the subjects of the school (teachers, management team) and university (research and scholarship).

Keywords: Municipal public school. Teachers in the early years. Management team.
\end{abstract}




\section{INTRODUÇÃO}

Em 2011 estabelecemos uma parceria com uma escola pública municipal que tem nos proporcionado momentos de reflexão e aprendizagens sobre a realidade da educação básica. Em 2014 iniciamos uma pesquisa intervenção que buscou identificar as necessidades formativas dos profissionais que atuam numa escola pública municipal que subsidiaram ações de formação continuada junto aos professores, equipe gestora e funcionários da escola parceira.

Desse modo, este texto visa apresentar a opinião de um grupo de profissionais da educação, de uma escola pública municipal, a respeito do papel da escola pública municipal e dos professores dos anos iniciais do ensino fundamental.

\section{METODOLOGIA}

A pesquisa se insere na abordagem qualitativa e teve como instrumentos de coleta de dados a pesquisa bibliográfica e o questionário. Trabalhamos com 12 questionários, sendo 9 professores e 4 gestores, que foram identificados por dois símbolos. Inicialmente uma letra "G" que representa o gestor e a " $\mathrm{P}$ " para o professor; e um número dado aleatoriamente que representa o questionário.

Para traçar o perfil dos sujeitos pesquisados utilizamos questões fechadas que foram tabuladas manualmente. Para categorização e análise das questões abertas recorremos à técnica de análise de conteúdo (FRANCO, 2008), que é um procedimento de pesquisa que permite fazer inferências sobre qualquer um dos elementos da comunicação. Segundo Franco (op. cit.), a expressão verbal, seus enunciados e suas mensagens, podem ser considerados indicadores indispensáveis para a compreensão dos problemas ligados às práticas educativas e seus componentes psicossociais. Para tanto, elaboram-se as categorias a partir da análise da resposta escrita no questionário, o que exige constantes idas e vindas para compreender a resposta do sujeito. Está pesquisa foi aprovada pelo Comitê de Ética em Pesquisa (CEP) da FCT/UNESP como número 27133714.3 .0000 .5402$.

\section{RESULTADOS}

Organizamos o presente artigo em três tópicos, embasados nos dados obtidos pelo questionário. O primeiro tópico apresenta o perfil dos sujeitos da pesquisa, posteriormente a reflexão sobre o papel social da escola e do professor a partir da voz dos sujeitos pesquisados. 


\section{Perfil dos sujeitos da pesquisa}

Em relação ao perfil desses profissionais verificamos que $50 \%$ da equipe gestora e $44,5 \%$ dos professores encontram-se entre 35 a 39 anos de idade. Dos 9 professores pesquisados, temos apenas um professor do sexo masculino, e na equipe gestora todas são do sexo feminino.

Quanto ao estado civil toda equipe gestora é casada. Entre os professores temos $77,8 \%$ casados e $22,2 \%$ solteiros.

Em relação à formação dos profissionais pesquisados observamos que toda equipe gestora possui curso de Pedagogia, sendo que $50 \%$ frequentou instituições públicas e $50 \%$ instituições privadas. Apenas uma gestora possui curso de pós-graduação "lato sensu" em instituição pública. Quanto aos professores todos são formados em cursos de licenciatura, sendo que $60 \%$ cursaram Pedagogia, 10\% Ciências, 10\% Educação Física, 10\% Matemática e 10\% História. Dentre os cursos de graduação $30 \%$ frequentaram instituições públicas e $70 \%$ instituições privadas. Temos três professores com pós-graduação em instituições privadas, sendo um professor com mestrado e dois com especializações "lato sensu".

\section{Papel da escola a partir da voz dos sujeitos}

Ao perguntarmos para os professores da instituição, qual o papel da escola pública no ciclo I do ensino fundamental, as respostas que se sobressaíram foram as de que, a escola pública tem a função de alfabetizar, e ensinar conhecimentos para contribuir na formação do aluno para se tornar um cidadão que saiba os seus direitos e deveres.

Apresentamos abaixo algumas escritas dos professores.

Preparar os alunos, alfabetizando-os e consequentemente, serem leitores críticos, para que todos podem contribuir para uma sociedade em que possam, futuramente, estarem inseridos nela. (Sujeito P1)

Alfabetização, além de possibilitar o acesso as transformações sociais. (Sujeito P4).

Oferecer estrutura adequada e materiais para uma educação de qualidade. $\mathrm{Na}$ escola a base da educação formal É tratada no ciclo 1. (Sujeito P6).

Transmitir conhecimentos historicamente construídos propiciando aos alunos continuar seus estudos e compreender o mundo que os cerca. (Sujeito P7).

Formar a base para a formação do indivíduo: leitura, escrita, interpretação. (Sujeito P9).

Já para a equipe gestora a principal função da escola é favorecer o ensino de qualidade a todos, dando condições para prosseguirem seus estudos. Outras questões relevantes também apareceram, como:

Favorecer o ensino de qualidade a todos, dando condições para prosseguirem seus estudos. (Sujeito G1). 
Cumprir seu papel social de ensinar. (Sujeito G2).

Formar o aluno de modo integral e ensinar valores[...]. Ensinar a quatros operações matemáticas (Sujeito G3).

Atender a todos os alunos e alfabetizar na idade certa. (Sujeito G4).

Desse modo, ao compararmos as respostas obtidas através da equipe gestora e dos professores sobre o papel da escola pública percebemos que ambos compartilham das mesmas ideias. A maioria das respostas foca a ideia da escola ter o papel da transmissão de conhecimento, ou seja, para esse grupo de profissionais a escola possui como uma de suas principais funções ensinar e transmitir os conhecimentos básicos para os alunos, esquecendo-se que a escola também tem o papel de educar, formar o cidadão além de ensinar conteúdos científicos.

\section{Papel do professor a partir da voz dos sujeitos}

Ressaltamos ser importante que o professor tenha clareza da sua importância dentro da sala de aula, enquanto sujeito responsável por contribuir com o futuro de seus alunos. Assim, ao questionarmos a equipe gestora sobre o papel do professor na escola pública nos anos iniciais do ensino fundamental, as respostas foram as seguintes:

Oferecer condições para que o aluno alcance seu pleno desenvolvimento. (Sujeito G1).

Propor atividades, que favoreçam a aprendizagem dos alunos, ser mediador de discussões, favorecer a construção de conhecimentos, normas, valores. (Sujeito G3).

É o de planejar, estudar e garantir que os alunos aprendam. (Sujeito G2)

Ser aquele que atende a todos os alunos, sendo um facilitador, proporcionando condições para que todos possam aprender. (Sujeito G4).

Para os professores seu papel central é garantir a alfabetização integral dos alunos, e proporcionar uma formação crítica.

Ensinar o aluno a ler, escrever e interpretar textos, possibilitando que o educando de sequência em seus estudos. (Sujeito P1).

O professor precisa exercer sua função na sala de aula de ensinar, mediar discussões para o efetivo aprendizado. (Sujeito P6).

Além de construir a aprendizagem com os alunos tem que formar cidadãos participativos. (Sujeito P2).

\section{DISCUSSÃO}

Diante dos dados empíricos apresentados é relevante destacar o resultado da pesquisa bibliográfica que possibilitou algumas reflexões acerca do papel da escola e do professor.

A escola, como instituição social, representa o espaço propício para humanização, para formar pessoas críticas e reflexivas, capazes de entender seu papel como sujeito histórico e 
transformador, que possa compreender criticamente a sociedade em que vive e refletir sobre sua atuação nela. Assim a "escola constitui espaço privilegiado para esse aprendizado, e não apenas para ensinar a ler, a escrever e a contar, habilidades importantes, mas insuficientes para a promoção da cidadania" (LIBÂNEO, OLIVEIRA, TOSCHI, 2003, p. 145).

[...] uma escola que corresponda aos interesses populares não será, nunca uma escola que se limite a ensinar leitura, escrita, cálculo e outras noções elementares. Esta escola deverá ser, também, uma escola que discuta, ao mesmo tempo, o próprio conhecimento que está sendo transmitido, explicite os conceitos, os conteúdos ideológicos que estão sendo transmitidos (BEISIEGEL, 1988, p.21).

Para a Lei de Diretrizes e Bases da Educação Nacional (LDB), o papel da escola está explicitado no artigo 12 , sendo

Art. $12^{\circ}$. Os estabelecimentos de ensino, respeitadas as normas comuns e as do seu sistema de ensino, terão a incumbência de: I - elaborar e executar sua proposta pedagógica;

II - administrar seu pessoal e seus recursos materiais e financeiros;

III - assegurar o cumprimento dos dias letivos e horas-aula estabelecidas;

IV - velar pelo cumprimento do plano de trabalho de cada docente;

$\checkmark$ - prover meios para a recuperação dos alunos de menor rendimento;

VI - articular-se com as famílias e a comunidade, criando processos de integração da sociedade com a escola;

VII - informar os pais e responsáveis sobre a frequência e o rendimento dos alunos, bem como sobre a execução de sua proposta pedagógica. (BRASIL, 1996).

O professor é o principal responsável por oferecer um ensino que seja significativo para seus alunos, pois é ele quem convive e sabe das necessidades e dificuldades de seus alunos. "No entanto, é preciso que o professor conheça bem o espaço próprio de sua atuação, qual seja, a escola, tendo clareza acerca da função contraditória, que ela exerce na sociedade." (SILVEIRA, 1995, p 28).

Assim, é importante que o professor conheça bem seus alunos, suas condições econômicas, sócias e psicológicas, além de conhecer a região da escola, pois, conhecendo o lugar ele poderá contribuir de forma mais significativa de acordo com as necessidades locais. "O verdadeiro papel do educador numa sociedade cuja marca principal é a dominação de uma classe sobre a outra deva ser o de um agente social que se compromete com a transformação dessa sociedade em benefício dos oprimidos." (SILVEIRA, 1995, p. 26).

No artigo 13 da LDB, o professor tem a função de,

Art. 13‥ Os docentes incumbir-se-ão de: 
I - participar da elaboração da proposta pedagógica do estabelecimento de ensino;

II - elaborar e cumprir plano de trabalho, segundo a proposta pedagógica do estabelecimento de ensino;

III - zelar pela aprendizagem dos alunos;

IV - estabelecer estratégias de recuperação para os alunos de menor rendimento;

$\mathrm{V}$ - ministrar os dias letivos e horas-aula estabelecidos, além de participar integralmente dos períodos dedicados ao planejamento, à avaliação e ao desenvolvimento profissional;

$\mathrm{VI}$ - colaborar com as atividades de articulação da escola com as famílias e a comunidade. (BRASIL, 1996).

Sendo assim, uma das possibilidades do professor garantir que sua atuação seja de qualidade para com seus alunos, é buscar uma formação continuada, que the proporcione um processo constante do aprender a profissão, não como resultado do acúmulo de informação, mas como um momento de repensar as suas práticas e construir novos conhecimentos, que se constituem "por meio do estudo, da reflexão, da discussão e da confrontação das experiências dos professores", sendo de responsabilidade da instituição, mas também do próprio professor, afinal "o compromisso com a profissão requer que ele tome para si a responsabilidade com a própria formação" (LIBÂNEO, 2001, p. 191).

\section{CONCLUSÕES}

Para esse grupo de profissionais da educação em questão, a principal função da escola pública é a de transmissora de conhecimentos, no entanto, devemos partir da concepção de que a escola é a principal instituição responsável por formar seus alunos de maneira integral, no entanto,

A função transformadora da escola, na verdade, não é exercida de forma direta, imediata, mas de forma indireta e mediada. Trata-se da função mediadora da escola que consiste na sua possibilidade de proporcionar as massas populares o acesso aos conhecimentos e habilidades teóricos e práticos necessários para uma compreensão cientifica, rigorosa e crítica da realidade em que vivem, tornando-as, assim, melhor instrumentalizadas para a luta pela sua libertação. (SILVEIRA, 1995, p.25).

Para Libâneo (1998, p. 7-8) a escola deve tornar-se um espaço que articula os objetivos convencionais da escola-transmissão com o:

[...] desenvolvimento do pensamento autônomo, crítico e criativo, formação de qualidades morais, atitudes, convicções às exigências postas pela sociedade comunicacional, informática e globalizada: maior competência reflexiva, interação crítica com as mídias e multimídias, conjunção da escola com outros universos culturais, conhecimento e uso da informática, formação continuada 
(aprender a aprender), capacidade de diálogo e comunicação com os outros, reconhecimento das diferenças, solidariedade, qualidade de vida, preservação ambiental.

Paro (2007, p. 34) afirma que é papel essencial da escola à "formação da personalidade do educando em sua integralidade", articulando a aquisição de conhecimentos e a formação do cidadão na dimensão individual e social. O ensino de qualidade pode ser compreendido se a escola não desempenhar a sua função.

Para atingir esse papel social a escola precisa de um professor que tenha uma formação que corresponda a esse novo cenário educacional, um professor crítico e reflexivo, que seja capaz de:

Estar comprometido com as crianças que finalmente conseguiram adentrar as escolas;

Ser capaz de desenvolver um trabalho docente de qualidade numa escola para todos;

Ser um profissional com capacidade de inovação, de criação, de participação nos processos de tomada de decisões e de produção de conhecimentos e não simples técnico, reprodutor de conhecimentos e/ou monitor de programas pré-elaborados;

Ter vivenciado um processo formativo que the tenha garantido o acesso ao saber, ao saber fazer e ao saber ser (conhecimentos, habilidades, atitudes, valores...) e

Saber que o seu papel é fundamental e imprescindível para a construção de uma escola pública de melhor qualidade. (GHEDIN, ALMEIDA, LEITE, 2008, p.28-29).

Para tanto, esse professor precisa entender-se como um sujeito que encontra-se em constante processo de formação e que trabalha diretamente com os alunos, formando novas gerações, em um espaço específico, que é a escola.

Para que a escola possa realizar com sucesso a função descrita acima, são necessárias algumas características valorizadas por Libâneo, Oliveira e Toschi (2003), como: professores bem preparados com uma formação inicial e contínua qualificada, que lhes possibilite ter clareza de seus objetivos e conteúdos, usar metodologia adequada à matéria para oferecer condições de aprendizagem e viabilizar a avaliação contínua, ou seja, elaborar e desenvolver de forma crítica seus planos de ensino; a construção coletiva do Projeto Político-Pedagógico, que visa a descentralizar e democratizar a tomada de decisões pedagógicas, jurídicas e organizacionais na escola, buscando maior participação dos agentes escolares; instigante organização do processo de ensino e aprendizagem que motive a maioria dos alunos; papel significativo da direção e coordenação pedagógica proporcionando o trabalho coletivo e colaborativo; disponibilidade de 
condições físicas e materiais que possibilitem oportunidades concretas para aprender; estrutura curricular com conteúdos bem selecionados, bem como critérios adequados de distribuição; motivadoras condições de trabalho a todos os profissionais da escola para que possam cumprir suas tarefas com êxito; gestão democrática que possibilite a participação da comunidade na escola.

Nos dias atuais, a educação brasileira pública municipal apresenta grandes desafios, principalmente após a municipalização das escolas a partir de 1990, visto que muitas Secretarias Municipais de Educação não estavam preparadas para assumirem o ensino fundamental. Nesse sentido a parceria entre a escola e a universidade possibilita reflexões, discussões e busca coletiva de soluções para os inúmeros desafios do cotidiano escolar. Elaborar parcerias significa unir indivíduos que estão interessados em trabalhar juntos para atingir objetivos comuns. Orsolon (2009, p.179) ressalta que a parceria representa o "encontro de diferentes para realizar um projeto comum [...]. A relação de parceria supõe confiança mútua e cumplicidade, isto é, conversas, trocas, discussões dos problemas e assunção conjunta das decisões tomadas".

\section{REFERENCIAS}

BEISIEGEL, C. R. Política educacional e programas de alfabetização. Ideias, "A educação básica no Brasil e na América Latina: repensando sua história a partir de 1930". n. 1, p. 16-22. 1988.

BRASIL. Lei de Diretrizes e Bases da Educação Nacional n. 9.394, de 20 de dezembro de 1996. Estabelecer as diretrizes e bases da educação nacional.

FRANCO, M. L. P. B. Análise de Conteúdo. Brasília: Líber Livro, 2008. 80p. (Série Pesquisa, v. 6). GHEDIN, E, ALMEIDA, M I;. LEITE, Y U. F. Formação de Professores: caminhos e descaminhos da prática. Brasília: Líber Livros Editora, 2008.

LIBÂNEO, J. C. Adeus professor, adeus professora? Novas exigências educacionais e profissão docente. São Paulo: Cortez, 1998.

LIBÂNEO, J.C.; OLIVEIRA, J.F; TOSCHI, M.S. Educação Escolar: políticas, estrutura e organização. São Paulo: Cortez, 2003.

LIBÂNEO, J.C.Organização e Gestão da Escola: teoria e prática. Goiânia: Editora Alternativa, 2001, $260 \mathrm{p}$.

ORSOLON, L. A. M. Trabalhar com as famílias: uma das tarefas da coordenação. In: PLACCO, V M N S, ALMEIDA, L R. (Org.). O coordenador pedagógico e o cotidiano da escola. 6. ed. São Paulo: Edições Loyola, 2009, p. 177-183.

PARO, Vitor. Qualidade do ensino: a contribuição dos pais. 3. Reimpr. São Paulo: Xamã, 2007. 
SILVEIRA, R J. T. O professor e a transformação da realidade. Nuances- Revista do Curso de Pedagogia, Faculdade de Ciências e Tecnologia- UNESP, Presidente Prudente, v.1, n.1, p. 21-30, set. 1995. 